\title{
Utilization of single-use gowns reduces the incidence of postoperative infections
}

\author{
M Nedić ${ }^{*}$, H Gašparović ${ }^{2}$ L Svetina², K Čuljak', R Habeković ${ }^{2}$ \\ From 23rd World Congress of the World Society of Cardio-Thoracic Surgeons \\ Split, Croatia. 12-15 September 2013
}

\section{Background}

Gowns and drapes are used widely in health care facilities. Gowns have been used to minimize the risk of disease acquisition by health care providers, to reduce the risk of patient-to-patient transmission, and to maintain sterility during invasive procedures. The aim of this prospective randomized study is to compare the ability of single-use and reusable surgical gowns to protect against the infections during surgical procedures in the Department of Cardiac Surgery University Hospital Center Zagreb.

\section{Methods}

We conducted a prospective observational study. Group 1 consisted of patients protected with single-use surgical gowns during surgical procedures. Group 2 consisted of patients protected with reusable surgical gowns during surgical procedures. Information obtained preoperatively included demographic data, surgery related data and postoperative complication occurrence and outcome data. During recovery, the incidence of postoperative infections was observed. Six weeks postop, patients were examined for the occurrence of urinary tract infection, central vein catheter and wound infections, pneumonia, sepsis, and other non-specific infections.

\section{Results}

Correlation between groups and infection occurrence in a 6-week postpone period was analyzed. Odds ratio was used; OR 0.3214, CI (95\%) $=0.1273-0.8113, \mathrm{p}=0.0163$. Use of single-use gowns and drapes reduced the incidence of the primary adverse outcome. Among patients who developed infections, $58.82 \%$ of underwent coronary artery bypass graft surgery, $35.29 \%$ underwent valve related procedures, and $5.88 \%$ underwent other types of surgery.

\footnotetext{
* Correspondence: mislav.nedic@gmail.com

${ }^{1}$ The University of Zagreb, School of Medicine, Zagreb, Croatia

Full list of author information is available at the end of the article
}

\section{Conclusion}

The occurrence of infections is $67.86 \%$ lesser in group with single-use surgical gowns. More liberal use of singleuse gowns should be implemented in contemporary protocols designed to reduce the incidence of postoperative infections.

\section{Authors' details}

${ }^{1}$ The University of Zagreb, School of Medicine, Zagreb, Croatia. ${ }^{2}$ Department of Cardiac Surgery University Hospital Center Zagreb, Zagreb, Croatia.

Published: 11 September 2013

doi:10.1186/1749-8090-8-S1-P79

Cite this article as: Nedić et al:: Utilization of single-use gowns reduces the incidence of postoperative infections. Journal of Cardiothoracic Surgery 2013 8(Suppl 1):P79.
Submit your next manuscript to BioMed Central and take full advantage of:

- Convenient online submission

- Thorough peer review

- No space constraints or color figure charges

- Immediate publication on acceptance

- Inclusion in PubMed, CAS, Scopus and Google Scholar

- Research which is freely available for redistribution
() Biomed Central

\section{() Biomed Central}

